\title{
The Relationships between Organizational Learning Level, School Effectiveness and Organizational Citizenship Behavior
}

\author{
Müslim Alanoğlu ${ }^{1}$, Zülfü Demirtaş ${ }^{2}$ \\ ${ }^{1} \mathrm{PhD}$ Student of Dicle University Institute of Educational Sciences, Diyarbakir, Turkey \\ ${ }^{2}$ Lecturer of Firat University Institute of Educational Sciences, Elazig, Turkey \\ Correspondence: Müslim Alanoğlu, Dicle University Institute of Educational Sciences, Diyarbakir, 21100, Turkey.
}

Received: December 22, 2015 Accepted: January 6, 2016 Online Published: January 14, 2016

doi:10.11114/jets.v4i4.1262 URL: http://dx.doi.org/10.11114/jets.v4i4.1262

\begin{abstract}
The aim of this research is to determine the relationships between organizational learning levels of high schools; organizational citizenship behavior of managers and teachers and effective school characteristics of them based on the opinions of managers and teachers. The population of the research consists of managers and teachers serving at high schools in Diyarbakir city, Turkey, during 2013-2014 educational year. According to findings of the research, perception of managers and teachers on the learning school and effective school characteristic is at average level and their perception on organizational citizenship behavior is at high level. Learning school characteristic of high schools is a significant predictor of managers' and teachers' organizational citizenship behavior and as well as effective school characteristic of high schools. Moreover, organizational citizenship behavior of managers and teachers are predictors of effective school characteristic.
\end{abstract}

Keywords: effective school, learning organization, organizational citizenship behavior, teacher, structural equation model

\section{Introduction}

Learning, which means reflecting on the behavior the knowledge gained by improving cognitive capacity, for organizations, differently requires using gained knowledge at work and business, and making inferences from routine works which guide the behavior (Levitt \& March, 1998). Learning of organizations depends on the collective learning ability of teams and individuals and differs from learning as an individual or team. However, organizational learning is built on individual and team learning. It can still take place even if all members of the organization may not have learned the new knowledge. Organizational learning takes place when the majority of the organization realizes the potential benefit of the new knowledge and learns it (Huber, 1991). As organizations are not a community of individuals, organizational learning is also not the learning of individuals; rather organizations only learn from the knowledge and experience of individuals (Argyris \& Schön, 1978). Organizational learning represents a process where individuals learn the knowledge, share the knowledge with other members of the organization, mutually interpret this shared knowledge and eventually save in the organizational memory to be used by all members.

Social and economic changes taking place around organizations are precipitating elements of organizational learning, and the ability of adaptation to change can only be developed through organizational learning (Alas \&Vadi, 2006). The organization begins to learn after one of its units obtains knowledge and realizes that it might be beneficial to the organization (Huber, 1991).

Organizational learning is examined based on the ability of organization to adapt to its environment (Dibella, Nevis \& Gould, 1996), identifying and correcting mistakes, and developing the means of correction (Argyris, 1977). It is built upon past knowledge and experience existing in the organizational memory (Stata, 1989). Organizational learning creates tension between gained knowledge, already existing, and previously used knowledge (Crossan, Lane \& White, 1999), making it difficult to learn new knowledge due to strong efforts of workers to maintain their past experience and knowledge in the organizational memory.

Because of organizational learning, which involves a process that incorporates obtaining, spreading, interpreting and saving the knowledge in organizational memory for the purpose of using it (Huber, 1991); the eventual outcome 
achieved is learning organization. Learning organization is an organization which has the ability to correct its attitude, values and behavior in the light of the new knowledge and understanding that it obtains, creates or transfers (Garvin, 1993), whose members work in teams to achieve targets and continuously share knowledge and provide feedback to understand how close they are to targets (Aydın, 2012). Individuals in learning organizations constantly improve themselves to achieve the mutually desired future (Çalkavur, 2009). Learning organizations aim to reach the deepest values of people such as unity, interdependence, collective effort and intelligence by providing their workers opportunity to discover and apply their abilities (Töremen, 2001).

The developments in organization and management fields also affect schools that represent education-teaching organizations. As stated in Senge et al. (2014), schools can only become creative and lively in a sustainable way by adopting a learning direction. Thus, schools become effective as much as they increase their Learning School (LS) level.

It is an indisputable fact that schools comprised of staff collectively pursuing a common future will be one step ahead of other schools and succeed in today's competitive environment. Besides, competitive culture stemming from high pressure results in a vicious circle reduces student motivation and causes discontent in the society (Lee, 2010). These schools competing in a changing environment need to ensure that their staff engage in a continual learning to adapt to the environment. To create a learning school environment, a trust atmosphere should be created and teachers should be encouraged to create a common vision (Cheng \&Ko, 2012). The constant deployment of learning mechanisms is seen related to being a learning school, and learning schools are expected to be higher performers and more effective.

According to Senge (1993) organizational learning encourages unity of aims and strategic thinking, and improves organizational system approach. Team identity is developed because of individuals working, assisting and collaborating closely with his colleagues and increases tendency to show Organizational Citizenship Behavior (OCB). Workers of organizations who view and learn the conducted business and transactions within the scope of a system tend to see the works of their colleagues related to the works carried out by them. Therefore workers in learning organizations are expected to show higher OCB.

OCB is private, and individual work behavior contributing to the social and psychological environment of the organization facilitates achieving organizational targets (Organ, 1997). Should this behavior not exhibited, workers are not to be pressured into it or penalized for not displaying this particular behavior. OCB is assisting others voluntarily to ensure healthy development of organization without any promise of reward or guarantee. OCB covers the activities which improve the functioning of the organization as a whole (Bies, 1989). Functioning as a complete body has similarities to addressing learning organizations within the scope of a system framework. Workers are expected to show more OCB in learning organizations comprised of individuals who share a common vision, completed their self-development, and who are able to assess the work in the organization as a whole.

Having important and positive contributions to the organizational output such as work quality, efficiency and sustainable success, organizational citizenship behavior has performance-enhancing effects in individuals and organizations. Moreover, integrated citizenship behavior which emerges in the entire organization particularly contributes to individuals working together and enhances group performance (Podsakoff \& MacKenzie, 1997). OCB increase productivity of workers and managers; ensures sustainable organizational performance and enhances the organization's ability to adapt to changes in the environment (Podsakoff, Scott, Paine \& Bachrach, 2000).

Exhibition of OCB in schools which is necessary to survive in the increasingly competitive environment will help them to achieve their aims. In schools where teachers show high level of OCB, better-than-expected student output is expected because of improving educative environment in the class in line with the improvements in the school as a whole. Successful school systems show that the only way to improve student output is to improve class' education environment (Mansor, Darus \& Dali, 2013).

Better-than-expected personal and organizational performance can be achieved through high level OCB of teachers. Martinez (2012) states that teachers showing OCB are more effective in creating an influential teaching environment and making a difference in the lives of students. In addition, these teachers are more enthusiastic about their work and their satisfaction is high. By exhibiting high OCB, teachers want to make their schools a better place, improve the school climate, create a better school environment, and increase student success. On the other hand, if teachers feel they receive support when they take risk, they will endeavor more to surpass their capacity and make more attempts to achieve success. OCB of managers and teachers results in a more effective school environment and increasing academic achievement (Özdevecioğlu, 2003). Therefore OCB is one of the important factors which help schools to achieve targets and become successful.

Effectiveness, which is the eventual target in most studies in organizational research, is related to achieving goals. Since schools are organizations offering people as their output, it is an undeniable fact that School Effectiveness (SE) is far 
more important than all other organizations' effectiveness. It is vitally important for societies of today to keep up with the rapid changes caused by developments in science and technology in order not to disconnect from the world. Keeping up with the rapid changes will only be possible with educated people equipped with necessary knowledge and skills warranted by this era.

Schools indicate a broad social system which includes school area and local community forming the school (Schechter \& Qadach, 2011). Schools, which are accepted to be open systems expected to transform and offer their basic input humans as output to the society after nurturing them in a desired way, are one of the most important organizations of the society. Raising people of creative and productive thinking will benefit the society not only economically, but it will also contribute to the existence of individuals who will provide cultural and social benefits. The interest in education and schools increases every day due to their direct and indirect contributions to the society (Ada \& Baysal, 2012).

According to Lezotte (1993) schools need change basically due to changing expectations of countries and societies from schools, and due to changing population of public schools. Schools are forced to become learning organizations since they have to adapt to their changing environment. As learning organizations schools will develop processes, strategies and structures to provide effective learning in uncertain and unstable environments. The reform and innovation capacity of schools depends on the ability to work together and the application of knowledge related to teaching \& learning (Schechter \& Qadach, 2011). According to Hoy and Miskel (2010), school output, performance of managers, teachers and students, teacher quality, internal harmony, efforts, work satisfaction and performance output are indicators of SE. However, the real factor of SE is the teacher who is inside the learning environment and constantly mingles with students and we must pay more attention to him or her; According to Kim (2012), the self-esteem and good communication skills of teachers have important effects on the development of student skills and viewpoints. Doubtless, no matter how effective other factors are, schools cannot be called reasonably effective if teachers, who are in one-to-one contact with students, cannot create an effective class environment.

Effective school considers students' readiness levels at the start of study and provides more-than-expected development (Sammons \& Bakkum, 2011). Therefore effective school provides extra added value compared to student output of schools which accept students of similar readiness levels. Effective schools will create a generation which will not only prove their skills in the classroom but also possess sufficient skill and knowledge required for success (Kirk \& Jones, 2004). The performance of such a student group will be high to meet the expected high expectations from them.

In the literature, no research aiming to reveal the relationship among LS, OCB and SE is found. When considered from this point of view, it is thought that this research will contribute to related literature and be useful by filling the gap in that field. Because of development organizational learning capacities of the school, managers' and teachers' will demonstrate more OCB and schools display more characteristics of effective schools. Determining the relationships among them will make this research a pioneering study in the literature.

In the light of the discussion above, the aim of this research is to determine the nature of relationship between the level of teachers' organizational learning, and their perception of OCB and SE; and how these variables predict each other and how much variation they explain. Three hypotheses are developed for this aim:

H1: Organizational learning level of high schools significantly predicts the level of effective school characteristic.

H2: Organizational learning level of high schools significantly predicts the level of managers' and teachers' OCB.

H3: Managers' and teachers' OCB level significantly predicts the level of effective school characteristic of high schools.

The relationship between organizational learning and effective school characteristic of high schools and the OCB of staff is shown in the model constructed based on the literature review and assessment of models used in the literature.

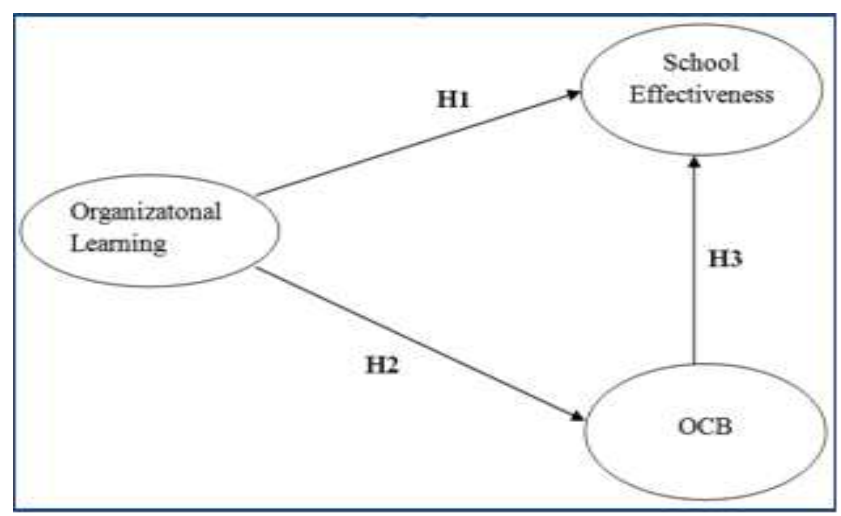

Figure 1. Models and hypotheses of research 


\section{Methodology}

Causal model is used in this research. The effect of organizational learning level in high schools on the OCB of managers, teachers, and on the effective school characteristic of schools is attempted to be determined through field literature survey and scales in this research.

\subsection{Population and Sample}

The population consists of school managers and teachers working at high schools in the four central districts of Diyarbakir city, Turkey, during 2013-2014 educational year. No sampling was carried out in this population as all high schools are included in the sample. A total of 2549 managers and teachers are serving in 53 high schools in four central districts of Diyarbakir, and scales used in the analysis are filled by 713 manager and teacher which were chosen randomly. The demographic characteristics of participants of the research are shown in Table 1.

Table 1. Demographic characteristics of participants

\begin{tabular}{lcc}
\hline Gender & $\mathbf{n}$ & $\mathbf{\%}$ \\
\hline 1.Famele & 259 & 36.3 \\
2.Male & 454 & 63.7 \\
Total & 713 & 100.0 \\
\hline Position & 627 & 87.9 \\
\hline 1.Teacher & 56 & 7.9 \\
2.Vice Manager & 30 & 4.2 \\
3.Manager & 713 & 100.0 \\
Total & & 87.5 \\
Education & 624 & 12.5 \\
1.Bachelors & 89 & 100.0 \\
Total & 713 & \\
\hline
\end{tabular}

Gender variable in Table 1 shows that $36.3 \%(n=256)$ of all participants are female and $63.7 \%(n=454)$ are male. Looking at the distribution of participants based on their positions at the school $4.2 \%(\mathrm{n}=30)$ are managers, $7.9 \%(\mathrm{n}=56)$ are vice managers and $87.9 \%(\mathrm{n}=627)$ are teachers. Distribution of the participants' education level shows that $87.5 \%$ $(\mathrm{n}=624)$ hold an undergraduate degree and $12.5 \%(\mathrm{n}=89)$ hold a postgraduate degree.

\subsection{Data Collection Scales}

Data was collected with questionnaires. Three different scales; learning schools, organizational citizenship behavior and effective school scales were used in data collection. Scales are applied to a group of 250 people from the same population to conduct exploratory and confirmatory factor analysis. Factor analysis is carried out with the obtained data, scale points which give error in modification indices are removed from scales to obtain better factor scores.

Learning Schools Scale: The scale used in this study is a version of the 42-item scale developed by Türkoğlu (2002) and used in Türkoğlu and Güçlü (2003), rearranged by Demirtaş (2014) in 24 points after conducting exploratory and confirmatory factor analysis. The 24-item scale consists of "Personal Mastery", "Mental Models", "Shared Vision", "System Thinking" and "Team Learning" dimensions. The results of exploratory factor analysis in Demirtaş (2014) showed a KMO value of .964 and Bartlett score of 7791.470 ( $\mathrm{p}<.05)$. Factor loadings ranged from .502 to .791 . The variation explained by the scale was $65.48 \%$. Confirmatory factor analysis of learning schools scale in this study indicated that the model is a good fit $\left(\mathrm{x}^{2} / \mathrm{df}=1.970 ; \mathrm{GFI}=0.89 ; \mathrm{AGFI}=0.86 ; \mathrm{CFI}=0.98 ; \mathrm{NFI}=0.97 ; \mathrm{RMSEA}=0.062\right.$ and SRMR= 0.051).

OCB Scale: Developed by Vey and Campbell (2004), and Williams and Shiaw (1999) to measure dimensions introduced by Organ (1988), this 19-item scale consists of Altruism, Conscientiousness, Courtesy, Sportsmanship and Civic Virtue dimensions. Basım and Şeşen (2006) conduct reliability analysis for two samples and find that Cronbach alpha scores for OCB sub-dimensions in the first sample are between .75 and .86 , and the total reliability of the scale is .89. The scores for the mentioned sub-dimensions in the second sample are between .77 and .87 , and the total reliability of the scale is calculated as .94 . Confirmatory factor analysis of OCB scale in this study shows that the model fit is acceptable $\left(\mathrm{x}^{2} / \mathrm{df}=3.033 ; \mathrm{GFI}=0.91 ; \mathrm{AGFI}=0.81 ; \mathrm{CFI}=0.94 ; \mathrm{NFI}=0.92 ; \mathrm{RMSEA}=0.123\right.$ and $\left.\mathrm{SRMR}=0.080\right)$.

Effective School Scale: Developed by Hoy (2009), this scale aims to measure the quality, amount, productivity, consistency and flexibility of output produced in a school. To test the validity of effective school scale, first the data fit for factor analysis is examined. Kaiser Mayer Orkin (KMO) and Bartlett tests are carried out to this aim. The KMO and Bartlett scores show that sample is sufficiently large and dataset is fit for factor analysis $(\mathrm{KMO}=.867$; Bartlett's Test of Sphericity $=1187.273 ; \mathrm{df}=28 ; \mathrm{p}=.000$ ). Exploratory factor analysis conducted for effective school scale shows that eight items of the scale form one factor. This scale explains 59.508\% of total variation. Cronbach alpha score of the scale is found as .903 . 
Confirmatory factor analysis conducted to test scores obtained in exploratory factor analysis does not produce acceptable scores $\left(\mathrm{x}^{2} / \mathrm{df}=73.77 ; \mathrm{GFI}=.80 ; \mathrm{AGFI}=.64 ; \mathrm{CFI}=.89 ; \mathrm{NFI}=.88 ; \mathrm{RMSEA}=.213\right.$ and SRMR $\left.=.076\right)$. Since the scores are not at the desired level, the test is repeated after the first item causing the largest error is removed from the scale based on modification indices. Obtained test scores improve, however, remain outside acceptable level following removal of the largest error. It is found that teachers and managers of the schools misinterpret the first item of the scale and do not view "output" term as "knowledge, skills, sentiments, attitude and behavior gained by students". This misunderstanding is considered to have influenced the data properties. In the second step, the eighth item causing the second largest error is removed and this time acceptable scores are obtained. Factor loadings ranged from .63 to .84 in the tested model after erroneous items are removed from the scale. Confirmatory factor analysis show that the model fits well to data $\left(\mathrm{x}^{2} / \mathrm{df}=4.972 ; \mathrm{GFI}=.94 ; \mathrm{AGFI}=.87 ; \mathrm{CFI}=.97 ; \mathrm{NFI}=.96 ; \mathrm{RMSEA}=.126\right.$ and $\left.\mathrm{SRMR}=.043\right)$.

Agreement intervals in scales are found using $(\mathrm{n}-1) / \mathrm{n}$ formula. The width of interval between 1 and 5 is calculated as 0.8 . The intervals for propositions in effective school and OCB are determined for "strongly disagree" as 1.00-1.80, for "mildly agree" as 1.81-2.60, for "somewhat agree" as 2.61-3.40, for "mostly agree" as 3.41-4.20, for "strongly agree" as 4.21-5.00; and for propositions in learning schools scales for "never" as 1.00-1.80, for "rarely" as 1.81-2.60, for "sometimes" as 2.61-3.40, for "generally" as 3.41-4.20, for "always" as 4.21-5.00.

\section{Findings}

The arithmetic mean and standard deviation of scales used in the research are shown in Table 2.

Table 2.Descriptive statistics of learning schools scale

\begin{tabular}{lccc}
\hline Learning School & n & $X$ & SS \\
\hline Personal Mastery & 713 & 3.159 & .983 \\
Mental Models & 713 & 3.406 & .826 \\
Shared Vision & 713 & 3.370 & .992 \\
System Thinking & 713 & 3.384 & .837 \\
Team Learning & 713 & 3.377 & 1.00 \\
Total & 713 & & .769 \\
\hline Organizational & Citizenship & & 3.372 \\
\hline Behavior & 713 & 3.688 \\
Altruism & 713 & 3.996 \\
Conscientiousness & 713 & 3.823 \\
Courtesy & 713 & 3.597 \\
Sportsmanship & 713 & 3.711 & .741 \\
Civic Virtue & 713 & 3,372 \\
Total & 713 & .798 \\
\hline School Effectiveness & & .801 \\
\hline Total & & & .747 \\
\hline
\end{tabular}

Statistics show that arithmetic average for Learning Schools is: $\overline{\boldsymbol{X}}=3.377$, for Mental Models: $\overline{\boldsymbol{X}}=3.517$, for Shared Vision: $\overline{\boldsymbol{X}}=3.406$, for Personal Mastery: $\overline{\boldsymbol{X}}=3.159$, System Thinking: $\overline{\boldsymbol{X}}=3.370$ and Team Learning: $\overline{\boldsymbol{X}}=$ 3.384. The opinions of teachers and managers on whether their school shows the characteristic of a learning school in LS scale, Personal Mastery, System Thinking and Team Learning dimensions are at "sometimes" interval (2.61-3.40). Participant opinions about Mental Models and Shared Vision are at "generally" interval (3.41-4.20). The relatively low standard deviation and high participant perception associated with Mental Models indicate a homogenous participant perception in Mental Models. The high perception of participants in Mental Models shows that participants tend to use their own cognitive capacity in the work carried out to solve problems in the school.

The arithmetic averages are; OCB, $\bar{X}=3.711$, Altruism, $\bar{X}=3.371$, Conscientiousness, $\bar{X}=3.688$, Courtesy, $\bar{X}=$ 3.823 and Civic Virtue, $\bar{X}=3.597$. Participant perceptions related to Altruism are at "somewhat agree" (2.61-3.40); Conscientiousness, Courtesy, Sportsmanship and Civic Virtue are at "mostly agree" (3.41-4.20) intervals. The level of participant perception related to Altruism dimension, which is defined as voluntarily assisting others for the benefit of the organization without seeking self-interest is found to be lower than perception levels for other dimensions. This may imply that teachers and managers consider their own benefit alongside organizational benefits to school in their 
behavior. In addition, the existence of a system which determines a teacher to replace those that avoid duty might be another reason of low participant perception related to this dimension.

The participant perceptions related to OCB ( $\overline{\boldsymbol{X}}=3.711)$ are "mostly agree" (3.41-4.20). OCB is exhibited by workers to the extent of the value attributed to it by the society they are raised in and the organizational culture they work at. The high participant perception related to this dimension may stem from prevalent commitment behavior and assisting each other in school culture. The positive results in the study related to OCB show that teachers and managers tend to exhibit voluntary behavior to ensure healthy development of the schools they work at. In addition, it may be inferred that teachers and managers are willing to assist their colleagues when it is beneficial for the school they work at.

Effective school scale ( $\bar{X}=3.372$ ) average shows that participant perceptions for SE is at "somewhat agree" interval (2.61-3.40). The fact that the perceptions of participants related to effective school characteristic of schools they worked at is "somewhat agree" shows that educational research, whose fundamental aim is to make schools more effective, need to focus more on this area and more commitment should be collectively made by society to make them more effective. It is important to improve effectiveness properties of schools, which are important part of the education system, to ensure that students participate in the society as qualified individuals and meet more of societal needs. Establishment of an effective school atmosphere primarily depends on the improvements in the relationship between school and family. Students, who are accepted as a measure of school output and effectiveness, are expected to graduate with the highest possible grades amongst peers, ascend to the upper levels or fuse with the society. This can only be achieved if school management works in coordination with parents and the vicinity of the school.

Structural Equation Model (SEM) is formed to test research hypotheses. Examination of relevant goodness of fit indices reveals that all goodness of fit scores indicate a good fit $\left(\mathrm{x}^{2} / \mathrm{df}=2.92 ; \mathrm{GFI}=.95 ; \mathrm{AGFI}=.93 ; \mathrm{CFI}=.99\right.$; NFI $=.98$; $\mathrm{NNFI}=.98 ; \mathrm{RMSEA}=.052$ and SRMR= .040). Obtained model fit scores show that the model is entirely significant. Goodness of fit statistics for structural equation model are shown in Table 3.

Table 3. Structural equation goodness of fit statistics

\begin{tabular}{lcc}
\hline Fit Measure & Value & Fit \\
\hline $\mathrm{x}^{2}(\mathrm{sd}=97)$ & 283.42 & Good Fit \\
RMSEA & .052 & Good Fit \\
SRMR & .040 & Good Fit \\
NFI & .98 & Good Fit \\
NNFI & .98 & Good Fit \\
CFI & .99 & Good Fit \\
GFI & .95 & Good Fit \\
AGFI & .93 & Good Fit \\
\hline
\end{tabular}

Critical N $(\mathrm{CN})=323.53$

The "Critical N" figure that assesses adequacy of sample shows the minimum number of participants need to be reached for this research. The critical $\mathrm{N}$ in the model is computed as 323.50. Since this study reaches 713 participants, the number of participants is sufficient for the research. The relationship between latent variables and observed variables in the structural equation model is shown in Figure 2.

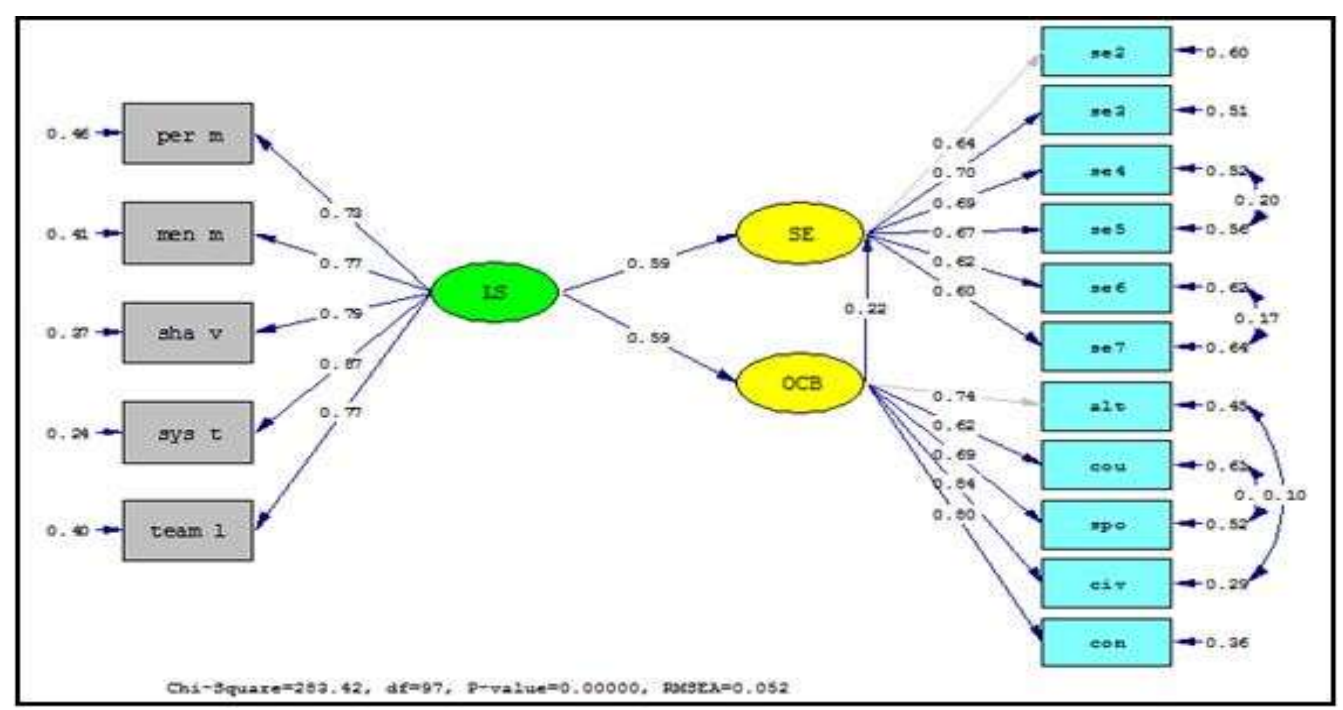

Figure 2. The basic model related to LS, OCB and effective school scales 
Analysis of related SEM reveals positive, direct and indirect relationships between LS level of high schools, OCB of staff and effective school properties of high schools. The results of the analysis are consistent with the hypotheses formed following relevant literature review and assessment.

H1: Organizational learning level of high schools significantly predicts effective school characteristic level.

One unit increase in organizational learning level of high schools results in 0.59 unit increase in effective school characteristic level and vice versa; one unit decrease in organizational learning level of high schools results in 0.59 unit decrease in school effectiveness level.

H2: Organizational learning level of high schools significantly predicts the level of OCB exhibited by managers and teachers.

One unit increase in organizational learning level of high schools results in 0.59 unit increase in workers' OCB level and vice versa; one unit decrease in organizational learning level of high schools results in 0.59 unit decrease in workers' OCB level.

H3: The level of OCB exhibited by managers and teachers significantly predicts the level of school effectiveness of high schools.

One unit increase in OCB level of managers and teachers results in 0.22 unit increase in school effectiveness level and vice versa; one unit decrease in OCB level of managers and teachers results in 0.22 unit decrease in school effectiveness level.

The LS level of high schools directly influences OCB exhibited by managers and teachers as well as effective school characteristic of high schools. Moreover, because LS characteristic influences exhibition of OCB by a ratio of 0.59 and OCB influences exhibition of effective school characteristic by a ratio of 0.22 , LS level of high schools indirectly influences level of SE by a ratio of $0.13(0.59 \times 0.22=0.13)$ (Kline, 2011). That means the LS level of high schools influences SE directly by a ratio of 0.59 and indirectly by a ratio of 0.13 , and by a ratio of 0.72 in total. In addition, although OCB of managers and teachers affects effectiveness of school they work at by a ratio of 0.22 , these two variables influence each other by a ratio of 0.57 .

Standard loadings (correlation coefficients), $\mathrm{t}$ values, $\mathrm{R}^{2}$ (coefficient of determination) and structural equations obtained from structural equations model are displayed in Table 4.

Table 4. Results of structural equations model

\begin{tabular}{|c|c|c|c|}
\hline Scales/Dimensions & Standard loadings & t-values & $\mathbf{R}^{2}$ \\
\hline \multicolumn{4}{|l|}{ Dimensions of SE } \\
\hline Personal Mastery & .73 & 22.08 & .54 \\
\hline Mental Models & .77 & 23.59 & .59 \\
\hline Shared Vision & .79 & 24.56 & .63 \\
\hline System Thinking & .87 & 28.53 & .76 \\
\hline Team Learning & .77 & 23.67 & .60 \\
\hline \multicolumn{4}{|l|}{ Dimensions of OCB } \\
\hline Altruism & .74 & & .55 \\
\hline Conscientiousness & .80 & 18.77 & .39 \\
\hline Courtesy & .62 & 15.02 & .48 \\
\hline Sportsmanship & .69 & 16.61 & .71 \\
\hline Civic Virtue & .84 & 24.91 & .64 \\
\hline \multicolumn{4}{|c|}{ Items of Effective Schools Scale } \\
\hline Item2 & .64 & & .40 \\
\hline Item3 & .70 & 14.65 & .49 \\
\hline Item4 & .69 & 14.46 & .48 \\
\hline Item5 & .67 & 14.04 & .44 \\
\hline Item6 & .62 & 13.32 & .38 \\
\hline Item7 & .60 & 12.92 & .36 \\
\hline \multirow{2}{*}{$\begin{array}{l}\mathrm{LS} \\
\mathrm{LS}\end{array} \longrightarrow \begin{array}{c}\mathrm{SE} \\
\mathrm{OCB}\end{array}$} & .59 & & \\
\hline & .59 & & \\
\hline $\mathrm{OCB} \longrightarrow \quad \mathrm{LS}$ & .22 & & \\
\hline \multicolumn{2}{|l|}{ Structural Equation } & Error Variance & $\mathbf{R}^{2}$ \\
\hline \multicolumn{2}{|l|}{$\mathrm{OCB}=.59 \times \mathrm{LS}$} & .59 & .34 \\
\hline \multicolumn{2}{|l|}{$\mathrm{SE}=.59 \times \mathrm{LS}+.22 \mathrm{OCB}$} & .50 & .55 \\
\hline
\end{tabular}

Examination of Table 4 reveals that variation associated to learning schools scale is mostly explained by System Thinking dimension $\left(R^{2}=0.76\right)$. Shared Vision $\left(R^{2}=0.63\right)$, Team Learning $\left(R^{2}=0.60\right)$, Mental Models $\left(R^{2}=0.59\right)$ and Personal Mastery $\left(\mathrm{R}^{2}=0.54\right)$ follow this dimension in a descending order. The variation associated with OCB is mostly explained by Sportsmanship dimension $\left(R^{2}=0.71\right)$, Civic Virtue $\left(R^{2}=0.64\right)$, Altruism $\left(R^{2}=0.55\right)$, Courtesy $\left(R^{2}=0.48\right)$ 
and Conscientiousness $\left(\mathrm{R}^{2}=0.39\right)$ dimensions follow Sportsmanship. The variation related to effective school scale is mostly explained by the third item $\left(R^{2}=0.49\right)$. The fourth $\left(R^{2}=0.48\right)$, fifth $\left(R^{2}=0.44\right)$, second $\left(R^{2}=0.40\right)$, sixth $\left(R^{2}=\right.$ $0.38)$ and seventh $\left(R^{2}=0.36\right)$ items follow this item in descending order.

The structural equations seen in Table IV show that learning school exogenous latent variable explains $34 \%$ of the variation $\left(\mathrm{R}^{2}=0.34\right)$ in organizational citizenship mediator variable at 0.05 significance level. In addition, learning school exogenous latent variable and OCB mediator endogenous latent variable explain $55 \%$ of the variation $\left(\mathrm{R}^{2}=0.55\right)$ in effective school endogenous latent variable at 0.05 significance level. In other words, $55 \%$ of effective school characteristic is explained by learning school characteristic and the level of OCB exhibited by managers and teachers of high schools.

\section{Discussion}

Due to globalization and many factors related to organizational field, organizations operating in all sectors have to respond to changes taking place in their environment (Akhtar, Arif, Rubi \& Naveed, 2011). For this reason, schools should also provide learning opportunities to their staff in order to respond to changes in their environment. According to Pedler, Burgoyn and Boydell (1991), learning organization is one which facilitates learning for all members of the organization and maintains sustainable transformation. Learning schools where a win-win situation exists for all of the school elements, whose environment reflect positive sentiments, and learning schools which rapidly solve limited number of conflicts in cooperation with other elements will not go back to finished work again (Hiatt-Mitchel, 2001) and these schools will be more effective than their peers.

The related literature shows that organizations (Morales, Montes \& Jover, 2006; Akhtar et al., 2011) and schools (Silins, Zarins \& Mulford, 2002) having properties of a learning organization are more effective than other organizations and schools. Consistent with the prior literature, this study documents that possession of learning school characteristics has effectiveness-increasing effects in schools and improves effectiveness.

Moreover, OCB is more frequently exhibited in learning organizations (Somech \& Drach-Zahavy, 2004; Chi-Cheng, Meng-Chen \& Meng-Shan, 2011; Basım, Şeşen, Sözen \& Hazır, 2009; Taşçı \& Koç, 2007). This study also shows that learning school characteristics have important effects on OCB of workers. This result indicates that learning schools are quite important to obtain successful and better-than-expected results. Establishing a learning school is however, associated with existence of an organizational culture supportive of learning (Popper \& Lipshitz, 2000).

This study finds that effects of OCB increase SE. The existence of teacher who constantly interacts with students who are at the centre of education process is important to form an effective school atmosphere. OCB exhibited by teachers positively affects and increases academic success of students (Khalid, Jusoff, Othman, İsmail \& Rahman, 2010). Every act and behavior of teachers will influence students who view them as a role model and students will form part of their character as a consequence. Therefore citizenship behavior of teachers will have a lot more effects on students who are output of their schools. Bogler and Somech (2005) state that citizenship behavior exhibited by teachers to students is also a sort of behavior assisting schools to become effective. Similarly, previous studies show that OCB has important effects on organizational performance (Podsakoff and MacKenzie, 1997; Podsakof et al., 2000) and school effectiveness (Özdevecioğlu, 2003; Martinez, 2012; Finnigan, Daly \& Stewart, 2012).

Teachers exhibiting effort-intensive behavior such as OCB will facilitate learning strategies of students (Khalid et al., 2010). In a study by Cooper (2010), there is a significant relationship between OCB and SE, however no significant relationship is found between SE, measured by student success, and OCB. These results show that OCB exhibited by teachers is quite important to achieve school targets and academic success. Therefore importance of OCB should be continuously emphasized and school cultures exhibiting this kind of behavior should be supported to obtain high performance output.

In this research, SEM is carried out to test the model formed by relevant literature review and assessment, and the model is validated. In the model, strong relationships are found between LS, OCB and SE. It is concluded that existence of a LS environment and exhibition of OCB by staff result in higher SE. Rendering schools effective is dependent upon possession of expected or above-expected qualifications by students who will be offered as output to the society or upper grade schools. Finding positive and significant relationships between learning school level of high schools, exhibition of OCB by staff members and effective school characteristic of high schools show that it is important to have a school environment supporting learning in schools to build an effective school environment.

\section{References}

Ada, Ş., \& Baysal, Z. N. (2012). Turkish Education System and Effective School Management (2nd ed.). In Turkish. Ankara: PEGEM Academy Publication.

Akhtar, S., Arif, A., Rubi, E., \& Naveed, S. (2011). Impact of organizational learning on organizational performance: 
study of higher education institutes. International Journal of Academic Research, 3(5, II), 327-331.

Alas, R., \& Vadi, M. (2006). The impact of organizational culture on organizational learning and attitudes concerning change from an institutional perspective.Int. J. Strategic Change Management, 1(1/2), 155-169. http://dx.doi.org/10.1504/IJSCM.2006.011109

Argyris, C. (1977). Double loop learning in organizations. Harvard Business Review, September-October, 115-124.

Argyris, C., \& Schön D. A. (1978). Organizational Learning: A Theory of Action Perspective (1st ed.). Massachusetts: Addison-Wesley.

Aydın, İ. (2012). Supervising in Teaching (3rd ed.). In Turkish. Ankara: PEGEM Academy Publication.

Basım, N. H., \& Şeşen, H. (2006). An adaptation and comparison of organizational citizenship behavior scale. In Turkish.Ankara University Institute of Social Sciences Journal, 61(4), 83-101.

Basım, N. H., Şeşen, H., Sözen, C., \& Hazır, K. (2009). The effect of employees' learning organization perceptions on organizational citizenship behavior. In Turkish. Selçuk University Institute of Social Sciences Journal, 22, 55-66.

Bies, R. J. (1989) Organizational Citizenship Behavior: The good soldier syndrome review. Academy of Management Review, 14(2), 294 -297.

Bogler, R., \& Somech, A. (2005). Organizational citizenship behavior in school how does it relate to participation in decision making? Journal of Educational Administration, 43(5), 420-438. http://dx.doi.org/10.1108/09578230510615215

Çalkavur, E. (2009). Trip of Learning Organization (3rd ed). In Turkish. İstanbul: Remzi Publication.

Cheng, E. C. K., \& Ko, P. Y. (2012). Leadership strategies for creating a learning study community. KEDI Journal of Educational Policy, 9(1), 163-182.

Chi-Cheng, C., Meng-Chen, T., \& Meng-Shan, T. (2011). The organizational citizenship behavior s and organizational commitments of organizational members influences the effects of organizational learning. International Journal of Trade, Economics and Finance, 2(1), 61-66.

Cooper, J. D. (2010). Collective Efficacy, Organizational Citizenship Behavior, and School Effectiveness in Alabama Public High Schools. Doctoral dissertation, The University of Alabama, Alabama.

Crossan, M. M., Lane, H. W., \& White, R. E. (1999). An organizational learning framework: from intuition to institution. The Academy of Management Review, 24(3), 522-537.

Demirtaş, Z. (2014). A scale development study for learning schools. Mevlana International Journal of Education (MIJE), 4(3), 1-12.

DiBella, A. J., Nevis E. C., \& Gould, J. M. (1996). Organizational Learning Style as a Core Capability. In Bertrand Moingeon and Amy Edmondson (Ed.). Organizational Learning and Competitive Advantage (38-56). California: SAGE Publications Ltd. http://dx.doi.org/10.4135/9781446250228.n3

Finnigan, K. S., Daly, A. J., \& Stewart, T. J. (2012). Organizational learning in schools under sanction. Education Research International, ID 270404, 1-10. http://dx.doi.org/10.1155/2012/270404

Garvin, D. A. (1993). Building a learning organization. Harvard Business Review on Knowledge Management.80-96. http://hbr.org /1993/07/building-a-learning-organization/ar/

Hiatt-Mitchel, D. B. (2001). Schools as learning communities: a vision for organic school reform. The School Community Journal, 11(2), 113-126.

Hoy, W. K. (2009). School Effectiveness Index. http://www.waynekhoy.com/school_effectiveness_index.html

Hoy, W. K., \& Miskel, C. G. (2010). Educational Administration Theory, Research and Practice.In Turkish.Ankara: Nobel Publication.

Huber, G. P. (1991). Organizational learning: the contributing processes and the literatures. Organizations Science, 2(1), 88-115. http://dx.doi.org/10.1287/orsc.2.1.88

Khalid, S. A., Jusoff, H. K., Othman, M., İsmail, M., \& Rahman, N. A. (2010). Organizational citizenship behavior as a predictor of student academic achievement.International Journal of Economics and Finance, 2(1), 65-71. http://dx.doi.org/10.5539/ijef.v2n1p65

Kim, J. (2012). A case study of the effects of educational welfare priority zone plan: why are its effects not confirmed by standardized test scores?. KEDI Journal of Educational Policy, 9(1), 91-111.

Kirk, D. J., \& Jones, T. L. (2004). Effective schools assessment report. http://images.pearsonclinical. com/images/PDF/ assessmentReports/ Effective Schools Final. pdf

Kline, R. B. (2011). Principles and Practice of Structural Equation Modeling (3rd ed.). New York: The Guilford Press.

Lee, Y. (2010). Views on education and achievement: Finland's story of success and South Korea's story of decline. 
KEDI Journal of Educational Policy, 7(2), 379-401.

Levitt, B., \& March, J. G. (1998). Organizational learning. Annual Review of Sociology, 14, 319-340. http://dx.doi.org/10.1146/annurev.so.14.080188.001535

Lezotte, L. W. (1993). Creating effective schools today and tomorrow.Journal for Quality and Participation, 16(1), 22-30.

Mansor, A., Darus, A., \& Dali, M. H. (2013).Mediating effect of self-efficacy on self-leadership and teachers' organizational citizenship behavior: A Conceptual Framework.International Journal of Economics Business and Management Studies, 2(1), 1-11.

Martinez, M. (2012). What Factors are Associated with a School's High Level of Organizational Citizenship Behavior? The Case of a Middle School Staff that Goes Above and Beyond.Doctoral dissertation, San Diego State University. San Diego.

Morales, V. J. G., Montes, F. J. L., \& Jover, A. J. D. (2006).Antecedents and consequences of organizational innovation and organizational learning in entrepreneurship.Industrial Management \& Data Systems, 106(1), 21-42. http://dx.doi.org/10.1108/02635570610642940

Organ, D. W. (1997). Organizational citizenship behavior: It's construct clean-up time. Human Performance, 10(2), 85-97. http://dx.doi.org/10.1207/s15327043hup1002_2

Özdevecioğlu, M. (2003). A study on the relationship between organizational citizenship behavior, some demographic characteristics of university students and academic success. In Turkish. Erciyes University Journal of the Faculty of Economics and Administrative Sciences, 20, 117-135.

Pedler, M., Burgoyn, J., \& Boydell, T. (1991). The Learning Company a Strategy for Sustainable Development (1st ed.). London: McGraw-Hill Book Company.

Podsakoff, M., Scott, B. M., Paine, J. B., \& Bachrach, D. G. (2000). Organizational citizenship behavior: acritical review of the theoritical and emprical literature and suggestions for future research. Journal of Management, 26(3), 513-563. http://dx.doi.org/10.1177/014920630002600307

Podsakoff, P. M., \& MacKenzie, S. B. (1997). Impact of organizational citizenship behavior on organizational performance: A review and suggestions for future research. Human Performance, 10(2), 133-151. http://dx.doi.org/10.1207/s15327043hup1002_5

Popper, M., \& Lipshitz, R. (2000). Organizational learning: mechanisms, culture, and feasibility. Management Learning, 31, 181.http://dx.doi.org/10.1177/1350507600312003

Sammons, P., \& Bakkum, L. (2011). Effective schools, equity and teacher effectiveness: a review to the literature, curriculum review and teacher training, 15(3), 9-26.

Schechter, C., \& Qadach, M. (2011). Toward an organizational model of change in elementary schools: the contribution of organizational learning mechanisms. Educational Administration Quarterly, 48(1), 116-153. http://dx.doi.org/10.1177/0013161X11419653

Senge, P. (1993). Transforming the practice of management.Human Resources Development Quarterly, $4,5-32$. http://dx.doi.org/10.1002/hrdq.3920040103

Senge, P., Cambron-McCabe, N., Lucas, T., Smith, B., Dutton, J., \& Kleiner, A. (2014). Schools that learn-A fith discipline resource. Crown Business.

Silins, H., Zarins, S., \& Mulford, B. (2002). "What characteristics and processes define a school as a learning organization? Is this a useful concept to apply to schools?. International Education Journal, 3(1), 24-32.

Somech, A., \& Drach-Zahavy, A. (2004).Exploring organizational citizenship behavior from an organizational perspective: the relationship between organizational learning and organizational citizenship behavior.Journal of Occupational and Organizational Psychology, 77, 281-298. http://dx.doi.org/10.1348/0963179041752709

Stata, R. (1989).Organizational learning-the key to management innovatio. Sloan Management Review, 30(3), 63-74. http://sloanreview.mit.edu/article/organizational-learning-the-key-to-management-innovation/

Taşçı, D., \& Koç, U. (2007). The relationship between organizational citizenship behavior s and organizational learning values: an ampirical research on academic personnel in Turkish. Anadolu University Journal of Social Sciences, 7(2), 373-382.

Töremen, F. (2001). Learning School (Alemdar). In Turkish. Ankara: Nobel Yayın Dağıtım.

\section{$(\mathrm{cc}) \mathrm{BY}$}

This work is licensed under a Creative Commons Attribution 3.0 License. 